\title{
Cognitive Behavior Therapy for Heart Failure Patients with Depression
}

\author{
Shancy Shabu1, Rasika Jayasekara² \\ ${ }^{1}$ Cardiac Step-DownWard, The Queen Elizabeth Hospital, Woodville South, Australia \\ ${ }^{2}$ School of Nursing \& Midwifery, University of South Australia, Adelaide, Australia \\ Email: Rasika.Jayasekara@unisa.edu.au
}

How to cite this paper: Shabu, S. and Jayasekara, R. (2019) Cognitive Behavior Therapy for Heart Failure Patients with Depression. Journal of Biosciences and Medicines, 7, 85-98.

https://doi.org/10.4236/jbm.2019.75012

Received: May 7, 2019

Accepted: May 14, 2019

Published: May 17, 2019

\begin{abstract}
The purpose of this systematic review was to examine the effectiveness of cognitive behavior therapy (CBT) in minimizing the depressive symptoms and improving quality of life in heart failure (HF) patients with depression. This systematic review was conducted in accordance with the Joanna Briggs Institute methodology for systematic reviews of effectiveness evidence. This review only considered randomized controlled trial, assessing the effectiveness of CBT as a treatment for depression in adults (aged above 18) with HF, compared with usual care, which may include medications. This systematic review includes five RCTs involving $379 \mathrm{HF}$ patients with depression $(\mathrm{CBT}=$ 192; Control = 187). Two RCTs compared CBT versus usual care using BDI, and no statistically significant differences were observed in reduction of depression after three months of the intervention (MD $-0.92,95 \% \mathrm{CI}-1.89$ to $-0.05)(p=0.06)$. However, a significant difference of depression level was identified between CBT and control groups in a meta-analysis of two RCTs after 6-months of intervention measured by Hamilton Depression Scale (HAM-D) (MD $-3.34,95 \%$ CI -5.00 to -1.68$)(\mathrm{p}=0.0001)$ with moderate heterogeneity (I2 $=43 \%)$. Quality of life was assessed at three months between intervening groups undergoing CBT and the control group with usual care in two RCTs. A statistically significant improvement was observed in the Minnesota Living with Heart Failure Questionnaire (MLHFQ) in the CBT group compared with usual care (MD -9.44, 95\% CI -13.02 to -5.87 ) ( $\mathrm{p}<$ 0.0001). The key finding of this review is that CBT is likely to be helpful in improving the depressive symptoms and quality of life in HF patients with depression. Moreover, long-term continued CBT sessions may help in minimizing the depression level and improving the QoL.
\end{abstract}

\section{Keywords}

Heart Failure, Depression, Cognitive Behavior Therapy, Systematic Review 


\section{Introduction}

Heart Failure (HF) is a complex clinical syndrome that results from a structural/functional impairment of one or both ventricles, resulting in the reduced ventricular ejection of blood from the ventricle in systole HF [1]. Current estimates suggest that approximately 26 million people worldwide live with chronic HF [1]. In Australia, it is estimated that 30,000 people receive a diagnosis of chronic $\mathrm{HF}$ each year [2] and prevalence of HF in Australia is similar to that of other industrialized countries, ranging between $1 \%-2 \%$ [3] [4]. A concerning trend that has been recently noted is that HF is starting to affect people at a younger age, with incident HF under 51 years of age doubling from three to $6 \%$ between years 2008-2012 [5]. HF comes with multiple burdens to the individual, health sectors and the economy. One of the burdens that emerge is the high cases of hospital admissions [6]. As a primary diagnosis, HF accounts for about $1 \%-4 \%$ of all hospital admissions in economically developed countries [4], and the economic cost of HF in Australia is estimated to be more than $\$ 1$ billion per annum [2]. HF also takes an immense personal toll on individuals. Chronic HF markedly affects patients' quality of life. Fear, anxiety, and depression are common, and work, travel and day-to-day social and leisure activities are difficult for those with breathlessness and extreme fatigue [2].

It has been argued that hospitalization for HF patients is more frequently due to comorbidities than HF-specific admissions [7]. There is a great deal of evidence to show that depression is prevalent comorbidity in patients with HF [8] [9] [10] [11]. Depression is a common comorbidity in HF, and approximately $48 \%$ of patients with HF have substantial depression [12]. Depression leads to an increase in the number of hospital admissions, diminishes the self-care abilities and worsens the quality of life of HF patients and increases the mortality [11]. The additional effect of depression on mortality in HF has been demonstrated in many studies over periods from three months to three years (short-term effect); however, the long-term impact of depression on clinical outcomes is not well known due to the early high mortality rate associated with HF [13] [14] [15]. The major psychological factor connected with HF progression is a depression [16]. Frequent hospitalizations, fluid restrictions, long-term use of medications and the number of health visits required can negatively impact on QoL, relationships, and ability to function in normal life activities and work capacity, leading to depression [17]. Depression may also lead to poor self-care maintenance and non-compliance with prescribed pharmacological and non-pharmacological therapies including medications and fluid restrictions [18] [19] [20].

Depression poses a dangerous impact on HF patients and is a major cause of suicide [19]. In some cases, depression in HF patients may be preventable and treating depression may help reduce the mortality rate [20]. Approaches that have been recommended for managing depression include practising relaxation, avoiding alcohol and drugs, staying active, connecting with others, psychotherapy and CBT [14]. There is also a range of antidepressant medications that are 
used to treat depression. However, antidepressants are not considered entirely safe for patients with HF [21] [22], and some evidence indicates worsening of the patients' prognosis [22] [23].

Cognitive behavior therapy (CBT) works on the assumption that individuals can positively influence their symptoms by changing their behavior and thought processes [24]. It also refers to the class of interventions sharing a common premise that both mental and psychological disorders are maintained by the presence of cognitive factors [14]. CBT may be advantageous in the treatment of depression and managing depressive symptoms among patients with HF [18]. It is evident that the cognitive therapy approach is effective in reducing symptoms of depression and, also in reducing hospital readmission rate and improving the Quality of life (QoL) of patients with HF [18]. CBT is a well-established intervention for depression and is currently recommended in clinical practice guidelines [25] [26], its effectiveness for depression in HF patients remains uncertain [20] [27]. CBT provides strong support for adult patients with depression [28] and older adults; [24] however, the effects of CBT in HF patients with depression should be further explored. Graven [14] suggested that further research is required to find the effect of CBT on HF patients with depression.

A preliminary database search (Cochrane Library, JBI Database of Systematic Reviews and MEDLINE and PROSPERO) was undertaken to identify any existing systematic reviews on this topic. Two systematic reviews related to this topic were identified; however, one systematic review includes a variety of study designs, including non-randomised studies and a poorly defined intervention and targeted population [29], and the other includes broadly defined interventions (e.g. psychological interventions) rather than being explicitly confined to CBT [30]. Given the prevailing uncertainty over the effectiveness of CBT as a treatment strategy for HF patients with depression, a comprehensive review of the efficacy and acceptability of CBT is required to inform and update clinical practice and future clinical guideline development.

\section{Method}

\subsection{Review Method}

The aim of this systematic review was to examine the effectiveness of CBT for heart failure patients with depression in healthcare settings. This systematic review was conducted in accordance with the Joanna Briggs Institute methodology for systematic reviews of effectiveness evidence [31]. The review title has been registered with the Joanna Briggs Institute. This systematic review protocol has been submitted for the publication on Nursing and Health Science (Manuscript ID is NHS-0379-2018).

\subsection{Inclusion and Exclusion Criteria}

This review only considered RCT's, assessing the effectiveness of CBT as a treatment for depression in adults (aged above 18) with HF, compared with usual care, which may include medications. HF was diagnosed using the New 
York Heart Association (NYHA) Functional Classification class two (mild), three (moderate), and four (severe), and depression was diagnosed according to the Diagnostic and Statistical Manual of Mental Disorders (DSM-IV) and the World Health Organization's International Statistical Classification of Diseases and Related Health Problems (ICD-10) criteria. This review considered primary outcomes as the level of depression measured using validated depression scales/tools such as the Beck Depression Inventory (BDI), Hamilton Depression Scale (HAM-D), Montgomery or Asberg Rating Scale. The secondary outcomes of interest were the psychological well-being of HF patients. In addition, studies that include the following secondary outcome measures were considered: HF patient's level of self-care maintenance, quality of life and hospital admission rate. For the purpose of this review CBT will be considered to be an intervention that includes 1) the recipient establishing links between their thoughts, feelings and actions with respect to the target symptom; 2) the correction of the person's misperceptions, irrational beliefs and reasoning biases related to the target symptom; 3 ) and either or both of the following: a) the recipient monitoring his or her own thoughts, feelings and behaviors with respect to the target symptom; and b) the promotion of alternative ways of coping with the target symptom [32]. In addition, if the intervention did not provide sufficient information, was considered 'less well defined' CBT. Studies were excluded if the study used overlapping populations with other disease processes (e.g. asthma, diabetes, hypertension) or cardiac interventions (e.g. heart transplant, cardiac stent).

\subsection{Search Strategy}

A three-step search strategy utilized in this review. An initial limited search of MEDLINE and EMBASE was undertaken followed by analysis of the text words contained in the title and abstract, and of the index terms used to describe the article. A second search using all identified keywords and index terms undertaken across all included databases. The search strategy was developed for use with Ovid MEDLINE and adapted for utilization in other databases such as EMBASE, and MEDLINE, EMCARE database, Joanna Briggs Institute Database of Systematic Reviews and Implementation Reports; Cochrane Library (Via Wiley), Scopus (Via Elsevier) and PsycINFO (via Ovid). The following registries were searched for ongoing and completed trials: ClinicalTrials.gov, US National Institutes of Health (NIH) http://clinicaltrials.gov/; International Clinical Trials Registry Platform (ICTRP), Word Health Organization (WHO) http://www.who.int/ictrp/en/; metaRegister of Controlled trials http://www.controlled-trials.com/. In addition, the search for unpublished studies included: ProQuest Dissertations and Theses, Google Scholar, Grey Literature Report (http://www.greylit.org). Thirdly, the reference lists of all identified RCTs were searched for additional studies.

\subsection{Data Extraction}

The papers retrieved from electronic databases were managed by EndNote Soft- 
ware (X8). After removing the duplicates, titles and abstracts were screened by two independent reviewers for assessment against the inclusion criteria for the review. Studies that met the inclusion criteria were retrieved in full and their details imported into the Joanna Briggs Institute System for the Unified Management, Assessment and Review of Information (JBI SUMARI) [31]. The full text of selected studies was retrieved and assessed in detail against the inclusion criteria by two independent reviewers. Quantitative data were extracted from RCTs using the standardized data extraction tool from JBI-MAStARI [31]. Authors of papers were contacted to request missing or additional data, where required. Authors of two unpublished studies were contacted to receive the study results; however, authors were unable to provide the requested data. Further discussions or third reviewer was used for disagreements arise from in between the reviewers.

\subsection{Data Synthesis}

Two independent reviewers critically appraised eligible studies for methodological validity before inclusion in the review using the Cochrane Collaboration tool described in the Cochrane Handbook for Systematic Reviews of Interventions [33]. Meta-analyses were performed using Review Manager 5 software [34]. For continuous outcomes, mean differences (MD) between the post-intervention values of the intervention and control groups were used to analyze the size of the effects of the interventions. Heterogeneity was assessed through examination of the forest plots and quantified using the I2 statistic. There was no evidence of statistical heterogeneity; a fixed effect model was used in the first instance to combine data. In addition, a descriptive narrative of included studies was provided to make a meaningful discussion.

\section{Findings}

\subsection{Study Selection}

A total of 869 papers were identified as potentially relevant to the review question in the first and second steps of the literature search. One additional article was identified from other resources. After removing duplicates, 689 papers were excluded based on the title and abstract of the papers. Twenty-five, papers that appeared relevant to the review topic were retrieved full-text papers for critical appraisal. Finally, five RCTs reported met the inclusion criteria were included in this review. A PRISMA flowchart presenting the study retrieval and selection process is shown in Figure 1.

\subsection{Description of Included Studies}

This systematic review includes five RCTs [10] [35] [36] [37] [38]. In all trials, participants were randomised to therapeutic (CBT) or control conditions. Included RCTs were conducted in USA ( $\mathrm{n}=3)$, Philippines $(\mathrm{n}=1)$ and Sweden $(\mathrm{n}=$ 1). Four RCTs compared CBT with usual care/standard care [35] [36] [37] [38], 


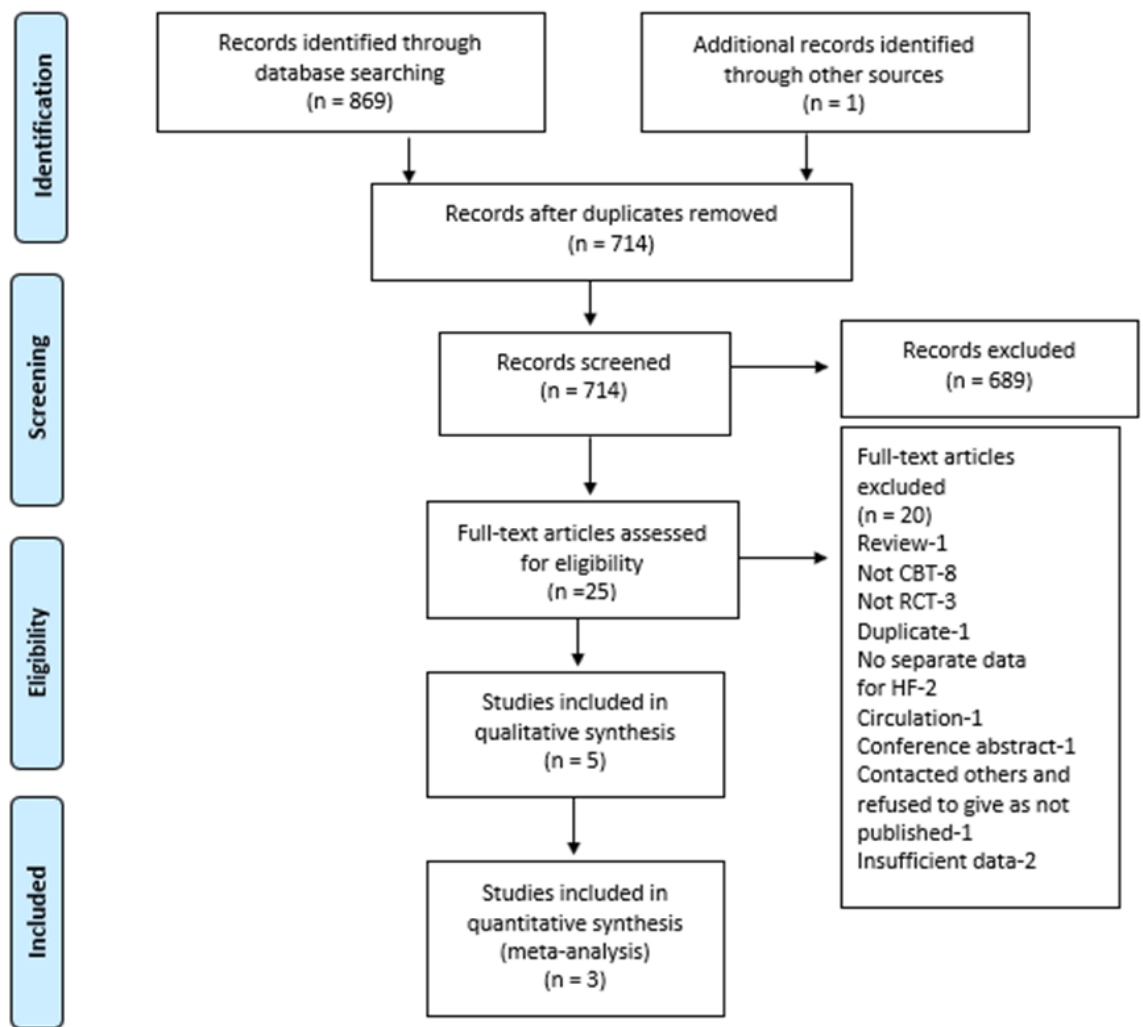

Figure 1. PRISMA 2009 flow diagram.

and other RCT used a web-based discussion forum as the comparator [10]. Included five RCTs involved a total of 379 participants $(\mathrm{CBT}=192$; Control $=187$ ) and all participants were HF patients with depression diagnosed by NYHA and depression diagnostic criteria. Four RCTs were conducted in community settings [10] [35] [36] [37] [38], and Dekker [36] were implemented in the hospital setting, however the follow-up was done in the community setting.

Included all RCTs were considered the low risk of selection bias as studies clearly reported a satisfactory randomization procedure [10] [35] [36] [37] [38]. Four studies provided the details of allocation concealment [10] [35] [36] [37]. Blinding of participants and clinicians was not possible due to the nature of CBT intervention; therefore, all include RCTs at high risk of performance bias. All studies were free from detection bias as the interventionist and outcome assessors were different and the details are provided in the method section. It can be judged at low risk of attrition bias in four studies that either conducted an intention to treat analysis or reported missing data balanced across groups and mostly reasons similar [10] [36] [37] [38]. All RCTs employed a CBT in addition to standard care. In four RCTs, Nurse-Led CBT [35]; Brief cognitive therapy [36], and CBTs [37] [38] compared with usual care or standard care. In one RCT, Internet-based CBT [10] compared with a discussion forum.

\subsection{Primary Outcome: Level of Depression}

Out of five RCTs, only three [36] [37] [38] were included in meta-analyses of 
depression. Dekker [36] and Freedland [37] compared CBT versus usual care using BDI, and no statistically significant differences were observed in reduction of depression after three months of the intervention (MD - $0.92,95 \% \mathrm{CI}-1.89$ to $-0.05)(\mathrm{p}=0.06)$. There was no evidence of heterogeneity (I2 =0\%) (Figure 2$)$. However, a significant difference of depression level was identified between CBT and control groups in a meta-analysis of Freedland [37] and Gary [38] after 6-months of intervention measured by Hamilton Depression Scale (HAM-D) $(\mathrm{MD}-3.34,95 \% \mathrm{CI}-5.00$ to -1.68$)(\mathrm{p}=0.0001)$ with moderate heterogeneity (I2 = 43\%) (Figure 3).

This review assessed the included five RCTs [10] [35] [36] [37] [38] individually because it is not possible summarized findings using meta-analysis. Table 1 summarizes the primary outcome (depression level).

\subsection{Secondary Outcomes: Quality of Life}

Quality of life was also assessed in the meta-analysis. Results of two RCTs were combined as both studies used the Minnesota Living with Heart Failure Questionnaire (MLHFQ) to measure the quality of life [36] [38]. Quality of life was assessed at three months between intervening groups undergoing CBT and the control group with usual care. A statistically significant improvement was observed in the HRQOL in the CBT groups (MD -9.44, 95\% CI -13.02 to -5.87) $(\mathrm{p}<0.0001)$ and a moderate heterogeneity was reported $(\mathrm{I} 2=39 \%)$ as depicted in Figure 4.

The quality of life was assessed in five RCTs [10] [35] [36] [37] [38] using two different tools (MLHFQ and Kanas City Cardiomyopathy Questionnaire (KCCQ). QoL measured at three months of Nurse-Led CBT with MLHFQ among 100 adult HF patients (37 - 74 yrs) in the Philippines by Cajanding [35] showed significant improvement in QoL $(\mathrm{p}<0.01)$ however, this RCT could not be used for the meta-analysis due to limited data. Dekker [36] conducted a study in 41 (Brief CT-20 and UC-21) adult HF patients (age $66 \pm 11$ ) at Kentucky,

\begin{tabular}{|c|c|c|c|c|c|c|c|c|c|c|c|c|c|}
\hline \multirow[b]{2}{*}{ Study or Subgroup } & \multicolumn{3}{|c|}{ CBT } & \multicolumn{3}{|c|}{ UC } & \multicolumn{3}{|c|}{ Mean Difference } & \multicolumn{3}{|c|}{ Mean Difference } & \\
\hline & Mean & SD & Total & Mean & SD & Total & Weight & IV, Fixed, $95 \% \mathrm{Cl}$ & & & IV, Fixed, $95 \% \mathrm{Cl}$ & & \\
\hline Dekker et al. (2012) & 9.3 & 1.6 & 20 & 10.1 & 1.7 & 21 & $91.5 \%$ & $-0.80[-1.81,0.21]$ & & & & & \\
\hline Freedland et al. (2015) & 16 & 10.7 & 79 & 18.2 & 10.5 & 79 & $8.5 \%$ & $-2.20[-5.51,1.11]$ & & & & & \\
\hline Total $(95 \% \mathrm{Cl})$ & & & 99 & & & 100 & $100.0 \%$ & $-0.92[-1.89,0.05]$ & & & 1 & & \\
\hline $\begin{array}{l}\text { Heterogeneity. } \mathrm{Chi}^{2}=0.6 \\
\text { Test for overall effect: } Z=\end{array}$ & $\begin{array}{l}3, d f=1 \\
1.87(P\end{array}$ & $\begin{array}{l}(P=0 . \\
=0.06)\end{array}$ & (13); $1^{2}=$ & $=0 \%$ & & & & & -100 & -50 & $\begin{array}{c}0 \\
{ }^{\circ} \text { CBT UC }\end{array}$ & 50 & 100 \\
\hline
\end{tabular}

Figure 2. CBT vs. UC: BDI scale (3 months).

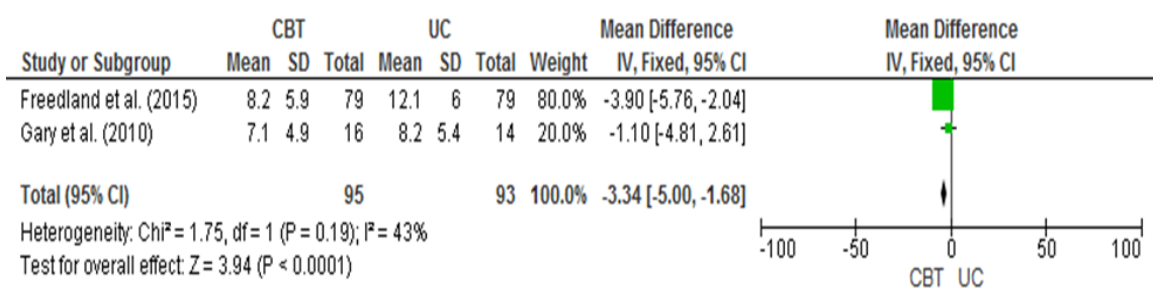

Figure 3. CBT vs. UC: HAM-D (6 months). 


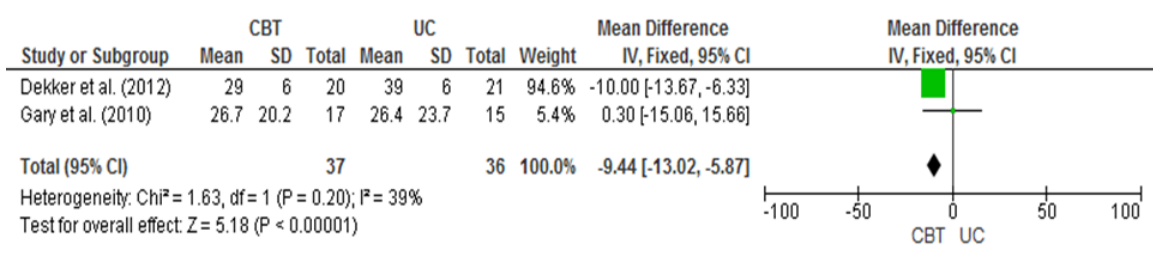

Figure 4. CBT vs. UC: MLHFQ (3 months).

Table 1. CBT vs. usual care: primary outcome: depression level.

\begin{tabular}{|c|c|c|}
\hline Study & Intervention & Key results-Depression \\
\hline $\begin{array}{l}\text { Cajanding (2016) } \\
\text { Philippines } \\
\text { Setting: Community }\end{array}$ & $\begin{array}{l}100 \text { Adult participants } \\
\text { (Age } 37-74 \text { yrs) } \\
\text { Nurse-Led CBT } \\
(\mathrm{n}=52) \\
\text { vs. Standard Care } \\
(\mathrm{n}=48)\end{array}$ & $\begin{array}{l}\text { Results at } 3 \text { months, mood score measured } \\
\text { by the CDS in the intervention group was } \\
\text { significantly improved compared with the } \\
\text { standard care group }(\mathrm{p}<0.01) .\end{array}$ \\
\hline $\begin{array}{l}\text { Dekker et al. (2012) } \\
\text { Kentucky, USA } \\
\text { Setting: Hospital }\end{array}$ & $\begin{array}{l}41 \text { adult patients } \\
\text { Age: } 66 \pm 11(\mathrm{SD}), \\
\text { Brief cognitive therapy } \\
(\mathrm{n}=20) \\
\text { vs. } \\
\text { Usual care }(\mathrm{n}=21) .\end{array}$ & $\begin{array}{l}\text { Results at } 3 \text { months, No significant } \\
\text { improvement in Depressive symptoms } \\
\text { measured by BDI-II in the CBT } \\
\text { intervention group. }\end{array}$ \\
\hline $\begin{array}{l}\text { Freedland et al. } \\
(2015) \\
\text { Washington DC, } \\
\text { USA } \\
\text { Setting: Community }\end{array}$ & $\begin{array}{l}158 \text { adult participants, } \\
\text { Age: } 55.8 \pm 11.2 \text {, } \\
\text { CBT plus usual care } \\
(\mathrm{n}=79) \text {, } \\
\text { Vs. Usual care }(\mathrm{n}=79)\end{array}$ & $\begin{array}{l}\text { Results at } 3 \text { months, Depression score meas- } \\
\text { ured by BDI-II score was not } \\
\text { significant in the CBT group. Depression } \\
\text { score measured with BDI-II at } 6 \text { months and } \\
1 \text { year showed significant improvement ( } \mathrm{p}= \\
0.008 ; \mathrm{p}=0.005 \text {, respectively). } \\
\text { Significant improvement noted in } \\
\text { depression at } 6 \text { months follow up of CBT } \\
\text { intervention on HAM-D and NIH } \\
\text { PROMIS measures }(\mathrm{p}<0.001) \text {. }\end{array}$ \\
\hline $\begin{array}{l}\text { Gary et al. (2010) } \\
\text { Georgia, USA } \\
\text { Setting: Community }\end{array}$ & $\begin{array}{l}74 \text { adult patients, } 4 \\
\text { groups, } \\
\text { Age: } 65.8 \pm 13 \\
\text { CBT: }(\mathrm{n}=16) \\
\text { Vs. Usual care: ( } \mathrm{n}= \\
\text { 14) }\end{array}$ & $\begin{array}{l}\text { Results at } 3 / 6 \text { months, No significant } \\
\text { improvement in depression score measured } \\
\text { by HAM-D in CBT intervention group. }\end{array}$ \\
\hline $\begin{array}{l}\text { Lundgren et al. (2016) } \\
\text { Sweden } \\
\text { Setting: Community }\end{array}$ & $\begin{array}{l}\text { 50, Adult participants, } \\
\text { Age }: 62.9 \pm 12.8 \\
\text { ICBT }(n=25) \text { vs. } \\
\text { DF }(n=25)\end{array}$ & $\begin{array}{l}\text { Results at } 9 \text { weeks of CBT intervention, no } \\
\text { significant improvement shown in primary } \\
\text { ANCOVA analysis }(p=0.21) \text {. In group } \\
\text { analysis, there was an improvement in de- } \\
\text { pression measured by PHQ-9 }(p=0.02) .\end{array}$ \\
\hline
\end{tabular}

USA revealed that brief CT made a significant improvement on QOL measured with MLHFQ at the first week of intervention $(\mathrm{p}<0.001)$ and no significant improvement showed at three months' time. The study conducted by Freeland [37] in Washington on 158 adult HF patients (age: $55.8 \pm 11.2$ ) revealed that CBT didn't help to improve QoL at the initial three months' time of CBT, however, there was a significant improvement in QoL measured by KCCQ at six months 
and 12 months' time ( $\mathrm{p}=0.02 ; \mathrm{p}=0.03$ respectively). RCT done by Gary [38] at Georgia in USA, among 30 adult $(65.8 \pm 13) \mathrm{HF}$ patients with intervention of CBT, and Lundergren [10] at Sweden on 50 adult $(62.9 \pm 12.8)$ HF patients with ICBT, showed no statistically significant improvement on QOL measured by MLHFQ at 12 weeks and six months [38], and nine weeks [10] time period of intervention.

\subsection{Other Outcomes}

Hospital admission rate was measured as an outcome in two RCT's [36] [37]. Dekker [36] conducted an RCT in 41 (Brief CT-20 and UC-21) adult HF patients (age $66 \pm 11$ ) at Kentucky; USA revealed that hospital admission rate was less in brief CT group compared to usual care at three months. However, there was no significant difference in Brief CT group compared to usual care $(\mathrm{p}=0.1)$. The study conducted by Freeland [37] in Washington on 158 adult HF (age: $55.8 \pm$ 11.2) found no statistically significant difference in hospital admission rate of CBT group compared to usual care $(\mathrm{p}=0.63)$ in one-year duration of intervention, and there is no separate data available for three months and six months.

Only one RCT evaluated self-care as an outcome. Freedland [37] measured self-care by HF index on self-care maintenance, and confidence among 158 adult HF patients (age: $55.8 \pm 11.2$ ) in Washington showed no significant improvement at three months, six months and one year.

\section{Discussion}

This systematic review focused on the improvement of depression and QoL in HF patients using CBT intervention than usual care. Five RCTs were included in this review [10] [35] [36] [37] [38]. Only three studies were able to include in meta-analysis due to variation in measuring scales and insufficient statistical data [36] [37] [38]. The result of the meta-analysis revealed that CBT has no significant effect on depression at three months. However, there is a substantial improvement at six months of CBT in HF patients' depressive symptoms compared to usual care. Whereas, the meta-analysis of QoL in HF patients showed significant improvement at three months of CBT intervention on QoL compared to usual care. The result of this systematic review and meta-analysis provide limited evidence that CBT is likely to be helpful in improving the depressive symptoms and quality of life in HF patients with depression. Findings from this review are consistent with other reviews on CBT. A review conducted by Jeyanantham and his colleagues also showed that CBT improves the depression signs and quality of life in HF patients [29]. Nekouei and his colleagues found that CBT intervention is an effective method for improving QoL in HF patients [39]. However, the small size of included trials, and the heterogeneity of the interventions has a considerable impact on generalizing these findings to HF patients with depression.

The duration of the CBT and different data collection methods used in the 
studies might have influenced the result of the review. A significant improvement was found in both depressive symptoms and QoL in the CBT group which used CBT sessions more than one hour per week [35]. The CBT sessions, one hour or less did not show significant improvement during the first three months [36] [37] [38]. However, a regular CBT with more than three months has shown a significant improvement in depression and QoL in HF patients with depression [37].

Gary [38] reported that the process of data collection in itself might have influenced the measuring depressive symptoms. The different measurement tools such as BDI, HAM-D, PHQ-9, and CDS were used to measure the depression level and have shown varying results. The RCT's mainly used self-rating depression scales (BDI, PHQ-9, and CDS) to collect baseline and follow up data [10] [35] [36] except the studies which used HAM-D [36] [37] to measure depression by a clinician. The reliability of self-reported depression rating scales may be limited due to both internal and external factors [40]. BDI was used in two different studies shown the same result at the same time duration [36] [37]. At the same time, same tools (HAM-D) used in two other studies shown different results at the same time of duration [37] [38]. Except for Cajanding [35] study which used CDS, all the other tools showed no significant improvement in depressive symptoms in CBT group compared to control group during the first three months [10] [36] [37] [38]. The QoL measured in different tools like MLHFQ and KCCQ also shown variation in all RCT results. Except for Cajanding [35], studies which used the same MLHFQ tool did not identify a significant improvement in QoL [37] [38]. The study which used KCCQ also did not find a significant improvement in QoL during three months' time interval [37]. However, these two tools used in the two different studies shown different result at six months' time duration [37] [38]. These findings are consistent with previous studies findings that commonly used depression measuring scales appeared to differ in their diagnoses for depression severity [41] [42]. Despite well-validated and standardized depressing measuring tools, the treatment planning solely based on data collected from a single self-report scale may be over-inclusive [41].

Included RCTs mainly utilized trained nurses as the interventionist to implement the CBT [10] [35] [36] [38]. It is evident that the selection of interventionist did not correlate with the results. Thereby, the implementation of CBT by trained nurses may be a viable option for treating HF in patients with depression. It would be economical and less time consuming to provide CBT during hospitalization of HF patients followed by CBT in the community by HF nurses. In future, it is recommended that all clinical nurses working in cardiac setting can be trained about the implementation of CBT to make it more practical and convenient for both the patients and clinicians.

Overall, it is difficult to make a reliable conclusion regarding which is the most effective form of CBT delivery methods because of a wide variety of CBT delivery methods, duration and number of sessions of included studies. Apart from the findings of this review, there are certain limitations that need to be 
recognized. This systematic review found only five RCTs assessing the effectiveness of CBT in HF patients with depression. The major drawback was the small sample size of some included RCTs that have prevented the detection of a statistically significant difference between the intervention and control group. Insufficiency of the long-term sustainability of CBT on patients is problematic as only one RCT shows follow up of more than 6 months' time. More vigorous RCTs are needed to establish the benefits of CBT in long-term. Moreover, cost efficacy of therapy is also needed to be ascertained.

\section{Conclusion}

The key finding of this review is that CBT is likely to be helpful in improving the depressive symptoms and quality of life in HF patients with depression. This review suggests that $\mathrm{CBT}$ plays a central role in improving the depressive symptoms and QoL in patients with HF. Moreover, long-term continued CBT sessions may help in minimizing the depression level and improving the QoL. However, the small size of included RCTs and the heterogeneity of the interventions has a considerable impact regarding generalizing these findings to broader clinical populations of HF patients with depression. From a clinical perspective, it can be suggested that psychological treatments derive from CBT can be used as a treatment strategy for depression in HF patients. Finally, the treatment choice for HF patients with depression should be based on the severity of HF and depression, CBT availability, the cost associated with CBT and patient preferences.

\section{Acknowledgements}

Authors sincerely thank Dr. Angela Kucia, Senior Lecturer of the University of South Australia, for her contribution to this systematic review project.

\section{Conflicts of Interest}

The authors declare no conflicts of interest regarding the publication of this paper.

\section{References}

[1] American Heart Association (2017) Causes of heart failure. In. (American HeartAssociation.

[2] National Heart Foundation. (2013) A Systematic Approach to Chronic Heart Failure Care: A Consensus Statement In. Melbourne, National Heart Foundation of Australia.

[3] Sahle, B.W., Owen, A.J., Mutowo, M.P., Krum, H. and Reid, C.M. (2016) Prevalence of Heart Failure in Australia: A Systematic Review. BMC Cardiovascular Disorders, 16, 32. https://doi.org/10.1186/s12872-016-0208-4

[4] Ponikowski, P., Anker, S.D., AlHabib, K.F., Cowie, M.R., Force, T.L., Hu, S., Jaarsma, T., Krum, H., Rastogi, V., Rohde, L.E., et al. (2014) Heart Failure: Preventing Disease and Death Worldwide. ESC Heart Failure, 2017. 
https://doi.org/10.1002/ehf2.12005

[5] Christiansen, M.N., Køber, L., Weeke, P., Vasan, R.S., Jeppesen, J.L., Smith, J.G., Gislason, G.H., Torp-Pedersen, C. and Andersson, C. (2017) Age-Specific Trends in Incidence, Mortality and Comorbidities of Heart Failure in Denmark 1995-2012. Circulation, 135, 1214-1223. https://doi.org/10.1161/CIRCULATIONAHA.116.025941

[6] Robertson, J., McElduff, P., Pearson, S.-A., Henry, D.A., Inder, K.J. and Attia, J.R. (2012) The Health Services Burden of Heart Failure: An Analysis Using Linked Population Health Data-Sets. BMC Health Services Research, 12, 103. https://doi.org/10.1186/1472-6963-12-103

[7] Roger, V.L. (2013) Epidemiology of Heart Failure. Circulation Research, 113, 646-659. https://doi.org/10.1161/CIRCRESAHA.113.300268

[8] Conley, S., Feder, S. and Redeker, N.S. (2015) The Relationship between Pain, Fatigue, Depression and Functional Performance in Stable Heart Failure. Heart \& Lung, 44, 107-112. https://doi.org/10.1016/j.hrtlng.2014.07.008

[9] Ghosh, R.K., Ball, S., Prasad, V. and Gupta, A. (2016) Depression in Heart Failure: Intricate Relationship, Pathophysiology and Most Updated Evidence of Interventions from Recent Clinical Studies. International Journal of Cardiology, 224 170-177. https://doi.org/10.1016/j.ijcard.2016.09.063

[10] Lundgren, J.G., Dahlström, Ö., Andersson, G., Jaarsma, T., Kärner, K.A. and Johansson, P. (2016) The Effect of Guided Web-Based Cognitive Behavioral Therapy on Patients with Depressive Symptoms and Heart Failure: A Pilot Randomized Controlled Trial. In JMed Internet Res., e194. https://doi.org/10.2196/jmir.5556

[11] Rustad, J.K., Stern, T.A., Hebert, K.A. and Musselman, D.L. (2013) Diagnosis and Treatment of Depression in Patients with Congestive Heart Failure: A Review of the Literature. Prim Care Companion CNS Disord, 15. https://doi.org/10.4088/PCC.13r01511

[12] Mbakwem, A., Aina, F. and Amadi, C. (2016) Expert Opinion-Depression in Patients with Heart Failure: Is Enough Being Done? Card Fail Rev, 2, 110-112. https://doi.org/10.15420/cfr.2016:21:1

[13] Adams, J., Kuchibhatla, M., Christopher, E.J., Alexander, J.D., Clary, G.L., Cuffe, M.S., Califf, R.M., Krishnan, R.R., O’Connor, C.M. and Jiang, W. (2012) Association of Depression and Survival in Patients with Chronic Heart Failure over 12 Years. Psychosomatics, 53, 339-346. https://doi.org/10.1016/j.psym.2011.12.002

[14] Graven, L.J., Martorella, G., Gordon, G., Grant Keltner, J.S. and Higgins, M.K. (2017) Predictors of Depression in Outpatients with Heart Failure: An Observational Study. International Journal of Nursing Studies, 69, 57-65. https://doi.org/10.1016/j.ijnurstu.2017.01.014

[15] Gathright, E.C., Goldstein, C.M., Josephson, R.A. and Hughes, J.W. (2017) Depression Increases the Risk of Mortality in Patients with Heart Failure: A Meta-Analysis. Journal of Psychosomatic Research, 94, 82-89. https://doi.org/10.1016/j.jpsychores.2017.01.010

[16] Kop, W.J., Synowski, S.J. and Gottlieb, S.S. (2011) Depression in Heart Failure: Biobehavioral Mechanisms. Heart Failure Clinics, 7, 23-38. https://doi.org/10.1016/j.hfc.2010.08.011

[17] Sobral Lacerda, M., Alves Cirelli, M., Leite de Barros, A.L.B. and de Lima Lopes, J. (2017) Anxiety, Stress and Depression in Family Members of Patients with Heart Failure. Revista da Escola de Enfermagem da USP, 51, 1-8. https://doi.org/10.1590/s1980-220x2016018903211 
[18] Ramos, S., Prata, J., Bettencourt, P., Goncalves, F.R. and Coelho, R. (2016) Depression Predicts Mortality and Hospitalization in Heart Failure: A Six-Years Follow-Up Study. Journal of Affective Disorders, 201, 162-170. https://doi.org/10.1016/j.jad.2016.05.024

[19] Chang, L.-Y., Wu, S.-Y., Chiang, C.-E. and Tsai, P.-S. (2017) Depression and Self-Care Maintenance in Patients with Heart Failure: A Moderated Mediation Model of Self-Care Confidence and Resilience. European Journal of Cardiovascular Nursing, 16, 435-443. https://doi.org/10.1177/1474515116687179

[20] Gaye, B., Canonico, M., Perier, M.-C., Samieri, C., Berr, C., Dartigues, J.-F., Tzourio, C., Elbaz, A. and Empana, J.-P. (2017) Ideal Cardiovascular Health, Mortality, and Vascular Events in Elderly Subjects: The Three-City Study. Journal of the American College of Cardiology (JACC), 69, 3015-3026.

https://doi.org/10.1016/j.jacc.2017.05.011

[21] O’Connor, C.M., Jiang, W., Kuchibhatla, M., Silva, S.G., Cuffe, M.S., Callwood, D.D., Zakhary, B., Stough, W.G., Arias, R.M., Rivelli, S.K., et al. (2010) Safety and Efficacy of Sertraline for Depression in Patients with Heart Failure: Results of the SADHART-CHF (Sertraline against Depression and Heart Disease in Chronic Heart Failure) Trial. J Am Coll Cardiol, 56, 692-699. https://doi.org/10.1016/j.jacc.2010.03.068

[22] Yekehtaz, H., Farokhnia, M. and Akhondzadeh, S. (2013) Cardiovascular Considerations in Antidepressant Therapy: An Evidence-Based Review. The Journal of Tehran Heart Center, 8, 169-176.

[23] Fosbol, E.L., Gislason, G.H., Poulsen, H.E., Hansen, M.L., Folke, F., Schramm, T.K., Olesen, J.B., Bretler, D.M., Abildstrom, S.Z., Sorensen, R., et al. (2009) Prognosis in Heart Failure and the Value of \{Beta\}-Blockers Are Altered by the Use of Antidepressants and Depend on the Type of Antidepressants Used. Circulation Heart failure, 2, 582-590. https://doi.org/10.1161/CIRCHEARTFAILURE.109.851246

[24] Jayasekara, R., Procter, N., Harrison, J., Skelton, K., Hampel, S., Draper, R. and Deuter, K. (2015) Cognitive Behavioural Therapy for Older Adults with Depression: A Review. Journal of Mental Health, 24, 168-171. https://doi.org/10.3109/09638237.2014.971143

[25] NICE (2009) Depression in Adults: Recognition and Management: Clinical Guideline. In. UK, National Institute for Health and Care Excellence (NICE).

[26] SIGN (2016) Management of Chronic Heart Failure. In. Scottish Intercollegiate Guidelines Network, Healthcare Improvement Scotland.

[27] Dekker, R.L. (2011) Cognitive Therapy for Depression in Patients with Heart Failure: A Critical Review. Heart Failure Clinics, 7, 127-141. https://doi.org/10.1016/j.hfc.2010.10.001

[28] Rubin, A. and Miao, Y. (2017) Within-Group Effect Size Benchmarks for Cognitive: Behavioral Therapy in the Treatment of Adult Depression. Social Work Research, 41, 135-144. https://doi.org/10.1093/swr/svx011

[29] Jeyanantham, K., Kotecha, D., Thanki, D., Dekker, R. and Lane, D.A. (2017) Effects of Cognitive Behavioural Therapy for Depression in Heart Failure Patients: A Systematic Review and Meta-Analysis. Heart Fail Rev, 22, 731-741. https://doi.org/10.1007/s10741-017-9640-5

[30] Lane, D.A., Chong, A.Y. and Lip, G.Y. (2005) Psychological Interventions for Depression in Heart Failure. The Cochrane Database of Systematic Reviews, Cd003329. https://doi.org/10.1002/14651858.CD003329.pub2

[31] Joanna Briggs Institute (2014) Joanna Briggs Institute Reviewers' Manual: 2014 Edi- 
tion. Adelaide: Joanna Briggs Institute (JBI).

[32] Jones, C., Cormac, I., Silveira da MotaNeto, J.I. and Campbell, C. (2004) Cognitive Behaviour Therapy for Schizophrenia. Cochrane Database of Systematic Reviews. https://doi.org/10.1002/14651858.CD000524.pub2

[33] Higgins, J.P.T. and Green, S. (2011) Cochrane Handbook for Systematic Reviews of Interventions. (Cochrane Collaboration)

[34] Review Manager [RevMan] (2011) In. Copenhagen, The Nordic Cochrane Centre, The Cochrane Collaboration.

[35] Cajanding, R.J. (2016) The Effectiveness of a Nurse-Led Cognitive-Behavioral Therapy on the Quality of Life, Self-Esteem and Mood among Filipino Patients Living with Heart Failure: A Randomized Controlled Trial. Applied Nursing Research, 31, 86-93. https://doi.org/10.1016/j.apnr.2016.01.002

[36] Dekker, R.L., Moser, D.K., Peden, A.R. and Lennie, T.A. (2012) Cognitive Therapy Improves Three-Month Outcomes in Hospitalized Patients with Heart Failure. $J$ Card Fail, 18, 10-20. https://doi.org/10.1016/j.cardfail.2011.09.008

[37] Freedland, K.E., Carney, R.M., Rich, M.W., Steinmeyer, B.C. and Rubin, E.H. (2015) Cognitive Behavior Therapy for Depression and Self-Care in Heart Failure Patients: A Randomized Clinical Trial. JAMA Intern Med, 175, 1773-1782. https://doi.org/10.1001/jamainternmed.2015.5220

[38] Gary, R., Dunbar, S., Higgins, M., Musselman, D. and Smith, A. (2010) Combined Exercise and Cognitive Behavioral Therapy Improves Outcomes in Patients with Heart Failure., J Psychosom Res 69, 119-131. https://doi.org/10.1016/j.jpsychores.2010.01.013

[39] Nekouei, Z.K., Yousefy, A. and Manshaee, G. (2012) Cognitive-Behavioral Therapy and Quality of Life: An Experience among Cardiac Patients. Journal of Education and Health Promotion, 1, 2. https://doi.org/10.4103/2277-9531.94410

[40] Kerr, L.K. and Kerr Jr., L.D. (2001) Screening Tools for Depression in Primary Care: The Effects of Culture, Gender, and Somatic Symptoms on the Detection of Depression. The Western Journal of Medicine, 175, 349-352. https://doi.org/10.1136/ewjm.175.5.349

[41] Zimmerman, M., Martinez, J.H., Friedman, M., Boerescu, D.A., Attiullah, N. and Toba, C. (2014) Speaking a More Consistent Language When Discussing Severe Depression: A Calibration Study of 3 Self-Report Measures of Depressive Symptoms. The Journal of Clinical Psychiatry, 75, 141-146. https://doi.org/10.4088/JCP.13m08458

[42] Zhao, Y., Chan, W. and Lo, B.C. (2017) Comparing Five Depression Measures in Depressed Chinese Patients Using Item Response Theory: An Examination of Item Properties, Measurement Precision and Score Comparability. Health and Quality of Life Outcomes, 15, 60. https://doi.org/10.1186/s12955-017-0631-y 